The Effect of Prechambers on Flame Propagation in a Natural-gas Powered Engine

S. R. Tonse

L. D. Cloutman

RECEIVED MAR O 11996

OSTI

August 1, 1995

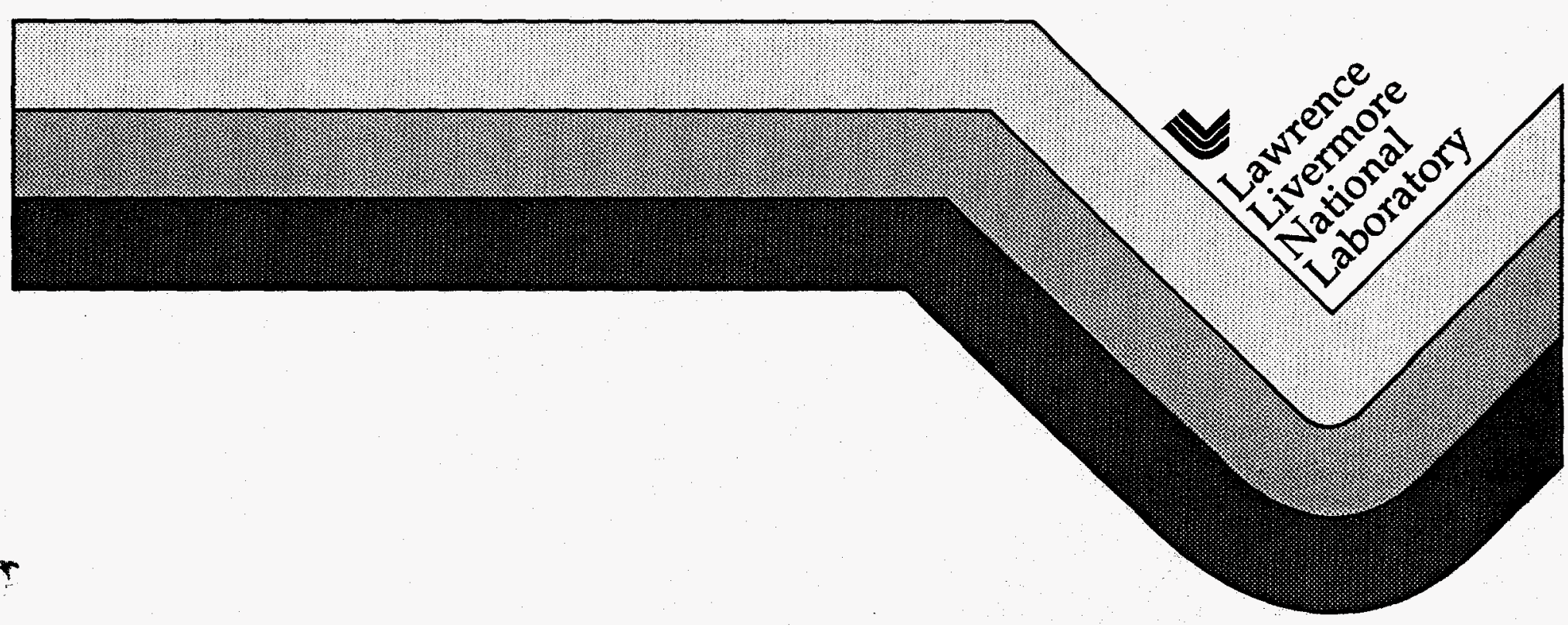




\section{DISCLAIMER}

This document was prepared as an account of work sponsored by an agency of the United States Government. Neither the United States Government nor the University of California nor any of their employees, makes any warranty, express or implied, or assumes any legal liability or responsibility for the accuracy, completeness, or usefulness of any information, apparatus, product, or process disclosed, or represents that its use would notinfringe privately owned rights. Reference herein to any specific commercial product, process, or service by trade name, trademark, manufacturer, or otherwise, does not necessarily constitute or imply its endorsement, recommendation, or favoring by the United States Government or the University of California. The views and opinions of authors expressed herein do not necessarily state or reflect those of the United States Government or the University of California, and shall not be used for advertising or product endorsement purposes.

Work performed under the auspices of the U.S. Department of Energy by Lawrence Livermore National Laboratory under Contract W-7405-Eng-48. 


\title{
The Effect of Prechambers on Flame Propagation in a Natural-gas Powered Engine
}

\author{
Shaheen R. Tonse and Lawrence D. Cloutman \\ Lawrence Livermore National Laboratory, \\ P.O.Box 808, Livermore, \\ CA 94550. \\ August 1, 1995
}

\begin{abstract}
The KIVA-3 computational fluid dynamics program was used to simulate the compression stroke, combustion, and power stroke in a natural-gas-fueled engine by solving the full Navier-Stokes equations. These calculations include cases with and without prechambers. Prechamber stoichiometry and spark locations were independently varied with the goal of understanding how various prechamber parameters influence the ignition of the fuel-air charge in the main chamber. The goal is to allow the use of very lean main-chamber charges to minimize nitrogen oxide $\left(\mathrm{NO}_{\mathbf{x}}\right)$ production. These calculations were performed in both two and three dimensions.
\end{abstract}




\section{Introduction}

Large-bore two-stroke natural-gas-fueled engines commonly are located along natural-gas pipelines, siphoning off a small portion of gas from the pipeline for use as a fuel, in order to pump the remaining gas along the pipeline. For the purpose of investigating the details of fuel burning and $\mathrm{NO}_{\mathrm{x}}$ production in such an engine we have used the reactive hydrodynamic computer code KIVA-3[1, 2, 3]. The strategy for controlling $\mathrm{NO}_{\mathbf{x}}$ emissions is to run with leaner mixtures, which have lower flame temperatures. However, the ability to reliably ignite lean mixtures limits how far this strategy can be carried in practice. It is known that the lean limit for smooth operation of these engines can be extended by using a prechamber with a nearly stoichiometric fuel-air mixture as the ignition source for the main chamber. This report explores the role of fluid mechanics in the enhancement of the ignition process and provides details not normally available to experimenters.

The simulation is an approximation of an actual experimental engine used by a research group at Colorado State University. The geometrical details have been reproduced, but other details like input gas flows, spark timings and positions are not known at this time. A more accurate representation will be forthcoming after an active collaboration has been established with the experimental group. The aim of this current simulation has been to obtain a general idea of the problem, to show that KIVA-3 can model it and to flush out in advance any pitfalls and problem areas. Also to learn about the factors which influence flame propagation in pre-chambers, which we have done.

KIVA-3 was written primarily to produce numerical solutions of the full nonlinear, transient, compressible-flow Navier-Stokes equations in two and three dimensions for the conditions found in internal combustion engines, although it is not restricted to those applications. The program includes moving boundaries, chemical reactions, and turbulence models. The numerical algorithm is based on the arbitrary Lagrangian-Eulerian (ALE) technique. The ALE technique splits each computational cycle into a partially implicit Lagrangian phase and into an optional rezoning phase which models advection as the grid moves in an arbitrary fashion with respect to the fluid. Lagrangian and Eulerian calculations are two special cases in ALE: omission of the rezoning phase results in a Lagrangian calculation, and moving the grid back to its original position on each cycle results in an Eulerian calcula- 
tion. Piston motion normally controls the grid motion in engine simulations, so that they are neither Eulerian nor Lagrangian.

The numerical simulations presented here assume the flow is axisymmetric. Hence we can use two-dimensional or three-dimensional-sector calculations. The chemistry is represented by a global fuel oxidation mechanism, the extended Zeldovich mechanism for thermal $\mathrm{NO}_{\mathbf{x}}$, and six equilibrium molecular dissociation reactions.

$$
\begin{aligned}
\mathrm{CH}_{4}+2 \mathrm{O}_{2} & \Rightarrow \mathrm{CO}_{2}+2 \mathrm{H}_{2} \mathrm{O} \\
O+\mathrm{N}_{2} & \Rightarrow \mathrm{NO}+\mathrm{N} \\
\mathrm{N}+\mathrm{O}_{2} & \Rightarrow \mathrm{NO}+\mathrm{O} \\
\mathrm{OH}+\mathrm{N} & \Rightarrow \mathrm{NO}+\mathrm{H} \\
\mathrm{O}_{2}+\mathrm{H}_{2} & \rightleftharpoons 2 \mathrm{OH} \\
\mathrm{O}_{2}+2 \mathrm{H}_{2} & \rightleftharpoons 4 \mathrm{OH} \\
\mathrm{O}_{2}+2 \mathrm{CO} & \rightleftharpoons 2 \mathrm{CO} \\
\mathrm{O}_{2} & \rightleftharpoons 2 \mathrm{O} \\
\mathrm{N}_{2} & \rightleftharpoons 2 \mathrm{~N} \\
\mathrm{H}_{2} & \rightleftharpoons 2 \mathrm{H}
\end{aligned}
$$

Turbulence is implemented through the $\mathrm{k}-\epsilon$ turbulence model[4].

The general outline of the remainder of this report is as follows: section 2 describes the governing equations, physical grid setup, and the procedure we adopt. Section 3 describes the numerical results, their analysis and conclusions. 


\section{Computational Procedure}

\subsection{The Governing Equations \& KIVA-3}

KIVA-3 based on the Navier-Stokes equations for a mixture of compressible gases. We use the mass weighted, single velocity representation.

Mass conservation is expressed by the continuity equation for each species $k$ :

$$
\frac{\partial \rho_{k}}{\partial t}+\nabla \cdot\left(\rho_{k} \vec{u}\right)=-\nabla \cdot \vec{J}_{k}+R_{k},
$$

where $\rho_{k}$ is the density of species $k, t$ is time, $\vec{u}$ is the velocity, and $R_{k}$ is the rate at which species $k$ is created by chemical reactions. The diffusional mass flux is given by Fick's law,

$$
\vec{J}_{k}=-\rho D \nabla\left(\rho_{k} / \rho\right)
$$

where $\rho$ is the total density, and $D$ is the species diffusivity. Since we are interested primarily in turbulent flows, we assume $D$ is independent of species. Eq. (1) may be summed over species to obtain the total continuity equation

$$
\frac{\partial \rho}{\partial t}+\nabla \cdot(\rho \vec{u})=0 .
$$

The momentum equation is

$$
\frac{\partial(\rho \vec{u})}{\partial t}+\nabla \cdot(\rho \vec{u} \vec{u})=\rho \vec{g}-\nabla P-\nabla \cdot \mathcal{T},
$$

where $\vec{g}$ is the gravitational acceleration, $P$ is the pressure, and $\mathcal{T}$ is the stress tensor

$$
\mathcal{T}=-\mu\left[\nabla \vec{u}+(\nabla \vec{u})^{T}\right]-\mu_{1} \nabla \cdot \vec{u} \mathcal{I} .
$$

Here $\mathcal{I}$ is the unit tensor, $\mu$ is the coefficient of viscosity, and $\mu_{1}$ is the second coefficient of viscosity, which we normally set equal to $-2 \mu / 3$ (that is, we assume the bulk viscosity is zero).

We choose to express energy conservation in terms of the specific thermal internal energy $I$ :

$$
\frac{\partial(\rho I)}{\partial t}+\nabla \cdot(\rho I \vec{u})=-P \nabla \cdot \vec{u}-\mathcal{T}: \nabla \vec{u}-\nabla \cdot \vec{q}+\sum_{k} H_{k} R_{k},
$$


where $\vec{q}$ is the diffusional heat flux, and $H_{k}$ is the heat of formation of species $k$. The heat flux is the sum of Fourier's law and enthalpy diffusion:

$$
\vec{q}=-K \nabla T+\sum_{k} h_{k} \vec{J}_{k}
$$

where $K$ is the conductivity, $h_{k}$ is the specific enthalpy of species $k$, and $T$ is the temperature.

The equation of state is the sum of partial pressures for each species treated as an ideal gas:

$$
P=\sum_{k} R \rho_{k} T / m_{k}
$$

where $R$ is the universal gas constant, and $m_{k}$ is the molecular weight of species $k$. The internal energy is given by

$$
\rho I=\sum_{k} \rho_{k} I_{k}(T)
$$

where the species thermal internal energies $I_{k}$ are functions of temperature derived from published tables of enthalpies[5, 6].

The general procedure during simulation is to set up a mesh in coordinate space describing the physical system, specifying the initial mixture of gases inside the cells. During the simulation run, production and concentrations of the various chemical species is monitored on a cell by cell basis, as well as temperature, pressure etc.

\subsection{Grid Setup}

The computational mesh set up for use in KIVA-3 (Fig.la \& b) is based upon an existing experimental engine at Colorado State University. The physical dimensions of the cylinder are much larger than those normally encountered in vehicle internal combustion engines, having a $35 \mathrm{~cm}$ bore and a $40 \mathrm{~cm}$ stroke. For the $2 \mathrm{D}$ setup a $40 \times 40$ mesh was used for the main chamber, giving a cell size of about $0.5 \mathrm{~cm} \times 1 \mathrm{~cm}$. The piston, with its raised lip, and the domed cylinder head were accurately reproduced, and in some of the simulations a pre-chamber was added to the top of the head. Both two and three dimensional grids were used in various simulations. In the prechamber, and in the pipe connecting the two chambers, the cell sizes were $0.15 \mathrm{~cm} \times 0.5 \mathrm{~cm}$ and $0.15 \mathrm{~cm} \times 0.3 \mathrm{~cm}$ respectively. The mesh contains $\approx 7000$ cells. Intake and exhaust ports have not been included. 


\subsection{Simulation Procedure}

The simulation commences at $180^{\circ}$ before top dead center (BTDC) with the cylinder containing a pre-mixed charge of $\mathrm{CH}_{4}$ and air. The piston moves up to TDC (with spark ignition occuring $10^{\circ} \mathrm{BTDC}$ ) and then returns to its starting position at the bottom, having executed the compression ${ }^{1}$ and power strokes at $300 \mathrm{rpm}$. An initial temperature of $400 \mathrm{~K}$ is used for both the charge and the "walls". Adiabatic compression has raised the gas temperature to $\approx 800 \mathrm{~K}$ by commencement of ignition. The spark duration is $7^{\circ}$ and is handled by adding energy to specified "ignition" cells for the duration. At various crank positions during each run, "snapshots" of the mesh, velocity vectors, temperature, pressure and species concentrations are made for every cell, and also on a global level.

Early runs were made without the pre-chamber, and rates of fuel consumption and $\mathrm{NO}_{x}$ production were recorded. The spark position was moved and its influence on the burning rate was noted. A pre-chamber $3 \mathrm{~cm}$ diameter and $5 \mathrm{~cm}$ high was then mounted at the very top of the cylinder dome connected to it by a narrow pipe with diameter $1.2 \mathrm{~cm}$. This vertical pipe connected the center of base of the pre-chamber to the top of the dome. (Planned later studies may have an angled pipe, and also a tangential attachment to the pre-chamber, to induce circulation in the pre-chamber during the compression stroke.) During the compression stroke gas speeds of $40 \mathrm{~m} / \mathrm{sec}$ are seen in the pipe. The intent is for ignition to occur first in the pre-chamber, raising its pressure and temperature, which has the effect of forcing the burning charge deep into the main cylinder volume. Generally following ignition, three phases (Fig.2 a,b,\& c) are observed: (a) The charge in the pre-chamber ignites, forcing hot charge into the cylinder. (b) The main cylinder combustion takes place, reversing the flow back into the pre-chamber and (c) After most combustion has completed, the downward piston motion pulls gas out of the pre-chamber.

In different runs the spark was moved to several positions inside the prechamber and also the stoichiometric composition of the prechamber was varied. The onset of combustion in the pre-chamber was found to be strongly influenced by existing gas flow about the ignition point, and several other factors, mainly geometrical. Rather than attempting to find a simple sys-

\footnotetext{
${ }^{1}$ On an IBM RS6000 workstation (AIX 3.2) KIVA-3 used about 90 minutes CPU time to go from $180^{\circ}$ BTDC upto the spark ignition time.
} 
tematic dependence of the onset of burning and the burning rate on these factors, each example is explained separately. Only for $\mathrm{NO}_{\mathbf{x}}$ can it straightforwardly be inferred that total production is larger for the cases where the onset of burning is earlier, ie. the high temperatures necessary to produce $\mathrm{NO}_{\mathbf{x}}$ are made available at higher cylinder pressures (concentrations).

\section{Simulation Results \& Analysis}

The results are divided into (a) No prechamber attached (b) Various spark positions inside prechamber and (c) Varying initial stoichiometry in prechamber, keeping spark position fixed.

\subsection{No prechamber attached}

Two runs were made without a prechamber attached. In these cases the spark positions were (1) At the very top of the cylinder dome and (2) one cm below that point. For spark position 2, the onset of burning is earlier but the duration is longer (Table 1 and Fig.3. Table 1 shows the crank angle intervals required (i) for $10 \%$ of the fuel to have burned after the commencement of spark ignition and (ii) for fuel consumption to go from $10 \%$ to $90 \%$. The same definitions apply to the $\mathrm{NO}_{\mathbf{x}}$ columns except that they are for production and not consumption). Fig. 4 shows the temperature profile of the grid at $0^{\circ}\left(10^{\circ}\right.$ after ignition for both cases). For a spark position too close to the wall the spread of flame can only be in one direction, i.e. a smaller number of cells are exposed to the spark, for the time period immediately following ignition. Position 1 also suffers from lower gas flows which convect heat to neighbouring cells, as it is close to a stagnation point. $\mathrm{NO}_{\mathrm{x}}$ production for these two cases is shown in Fig.5.

\subsection{Various spark positions inside prechamber}

For runs with the pre-chamber and with a uniform equivalence ratio of 0.7 throughout, sparks were initiated at $10^{\circ}$ BTDC in the following locations: (1) At the bottom of the chamber in an area sheltered from the flow through the pipe (2) At the top corner of the chamber. This was run for both two and three dimensional cases and (3) At the bottom of chamber, but directly 
exposed to the flow in the pipe. The results of these runs show large variations amongst themselves, as summarized in Table 1 and Figs.6,7 \& 8 .

Spark position 1: During the compression stroke a small circulating current arises in the pre-chamber, rising up the central axis, flowing outward along the top boundary, down the left and right boundaries, and then inward along the bottom boundary. This causes cells inward of the spark to ignite and the flame spreads toward the pipe. When it reaches the pipe it is sufficiently hot and the pipe-flow has become small enough that the flame ignites cells both downward into the pipe and upward into the pre-chamber. Thus the flame reaches the main chamber at a very early time.

Spark Position 2: Here the flame spreads mostly to neighboring cells and as a result the pre-chamber is fully ignited before the flame proceeds down the pipe. This case was done in three dimensions also. For the $3 \mathrm{D}$ case, onset was slower and duration was longer, as we expect, since a $2 \mathrm{D}$ ignition point is in actuality a ring.

Spark Position 3: Attempting to ignite a cell directly in the path of the high-speed gas flow up the pipe, caused heat to be convected to cells downstream of it. The onset of ignition was delayed as heat was dissipated, and finally occurred a few cells above the ignition point. Once ignition was established, this case was similar to spark position 2 .

Figs.6,7 \& 8 show the time evolution of the burn for the three 2-dimensional cases described above. For spark position 1 we can see that the flame front is well into the main chamber even before the whole prechamber has been lit.

Finally Fig.9 shows temperature profiles similar to those of Fig.7 except that they are taken at times when $90 \%$ of the fuel has been burnt (different for each spark position). The similarity between the burn patterns shows that the large differences in pre-chamber burn patterns does not carry through to the main chamber, except for matters of timing.

\subsection{Varying initial stoichiometry in prechamber}

Several runs were made with the spark in position 2 described in section 3.2 , but with a rich mixture initially filling the prechamber. During the compression stroke, leaner charge coming in from the main chamber reduces the equivalence ratio in the prechamber, nevertheless it is still slightly higher at the time of ignition, and this enhances burning. However, as can be seen 
from Figs.10a \& $\mathrm{b}$ the difference in fuel burn rate is only significant at early times, and is washed away as the main chamber ignites. The usefulness of this may be limited to borderline cases where the main chamber is too close to the lean flammability limit for reliable combustion be it not for the enriched prechamber. (We will explore this in later simulations.)

\section{Conclusion}

KIVA-3 was used to simulate the compression and power strokes in a generic, 2-cycle, natural-gas-fueled, large-bore engine. The effect of a pre-chamber and spark location on flame propagation was studied. We found that the details of the combustion event depend sensitively on such details. Most importantly, we find that the fluid dynamics of the hot combustion products jetting from the pre-chamber is a major factor in enhancing combustion in the main chamber. Not only does the jet provide a larger, more energetic flame kernel than a spark plug, it also increases turbulent mixing in the main chamber.

It is apparent that KIVA-3 provides a useful tool for the simulation of a firing natural gas engine as described above. This program includes details of the engine geometry, fluid flows, and chemical reactions, which influence one another in complex, often non-intuitive ways. The computer program provides detailed maps of velocities, composition and thermodynamic variables, that that can be compared with experimental data. Even these preliminary solutions provide a level of insight into the physics of engine operation that might be difficult to glean from global experimental data such as pressure histories and $\mathrm{NO}_{x}$ concentrations in the exhaust system. The next step is to actively collaborate with an experimental group to quantitatively check the accuracy of the calculations and perhaps provide guidance for the experiments. 


\section{References}

[1] A. A. Amsden, KIVA-3: A KIVA Program with Block-Structured Mesh for Complex Geometries. Los Alamos National Laboratory report LA12503-MS

[2] A. A. Amsden, J. D. Ramshaw, P. J. O'Rourke, and J. K. Dukowicz, KIVA: A computer program for two- and three-dimensional fluid flows with chemical reactions and fuel sprays. Los Alamos National Laboratory report LA-10245-MS (1985).

[3] A. A. Amsden, J. D. Ramshaw, L. D. Cloutman, and P. J. O'Rourke, Improvements and extensions to the KIVA computer program. Los Alamos National Laboratory report LA-10534-MS (1985).

[4] B.E.Launder and D.B.Spalding, Mathematical Models of Turbulence (Academic Press, New York, 1972).

[5] D. R. Stull and H. Prophet, JANAF Thermochemical Tables, 2nd ed. (U. S. Department of Commerce/National Bureau of Standards, NSRDSNBS 37, June 1971).

[6] M. W. Chase, J. L. Curnutt, A. T. Hu, H. Prophet, A. N. Syverud, and L. C. Walker, JANAF thermochemical table, 1974 supplement. J. Phys. Chem.Ref. Data $\underline{3}, 311$ (1974). 
Table 1: Rates of $\mathrm{CH}_{4}$ burning and $\mathrm{NO}_{\mathbf{x}}$ Production

\begin{tabular}{|c|c|c|c|c|}
\hline Case & \multicolumn{2}{|c|}{$\mathrm{CH}_{4}$ Burn } & \multicolumn{2}{|c|}{$\mathrm{NO}_{\mathrm{x}}$ Production } \\
\hline & $\Delta \theta_{d}(10 \%)$ & $\Delta \theta_{b}(10-90 \%)$ & Onset (10\%) & Duration $(10-90 \%)$ \\
\hline \multicolumn{5}{|l|}{ With Pre-chamber } \\
\hline Spark Pos. 1 & $18^{\circ}$ & $19^{\circ}$ & $22^{\circ}$ & $8^{\circ}$ \\
\hline$\overline{\text { Spark Pos. } 2 \text { (3D) }}$ & $27^{\circ}$ & $19^{\circ}$ & $32^{\circ}$ & $12^{\circ}$ \\
\hline$\overline{\text { Spark Pos. } 2 \text { (2D) }}$ & $23^{\circ}$ & $13^{\circ}$ & $28^{\circ}$ & $10^{\circ}$ \\
\hline Spark Pos. 3 & $26^{\circ}$ & $20^{\circ}$ & $31^{\circ}$ & $12^{\circ}$ \\
\hline \multicolumn{5}{|c|}{ Without Pre-chamber } \\
\hline Spark Pos. 1 & $30^{\circ}$ & $17^{\circ}$ & $37^{\circ}$ & $11^{\circ}$ \\
\hline Spark Pos. 2 & $23^{\circ}$ & $20^{\circ}$ & $27^{\circ}$ & $9^{\circ}$ \\
\hline
\end{tabular}



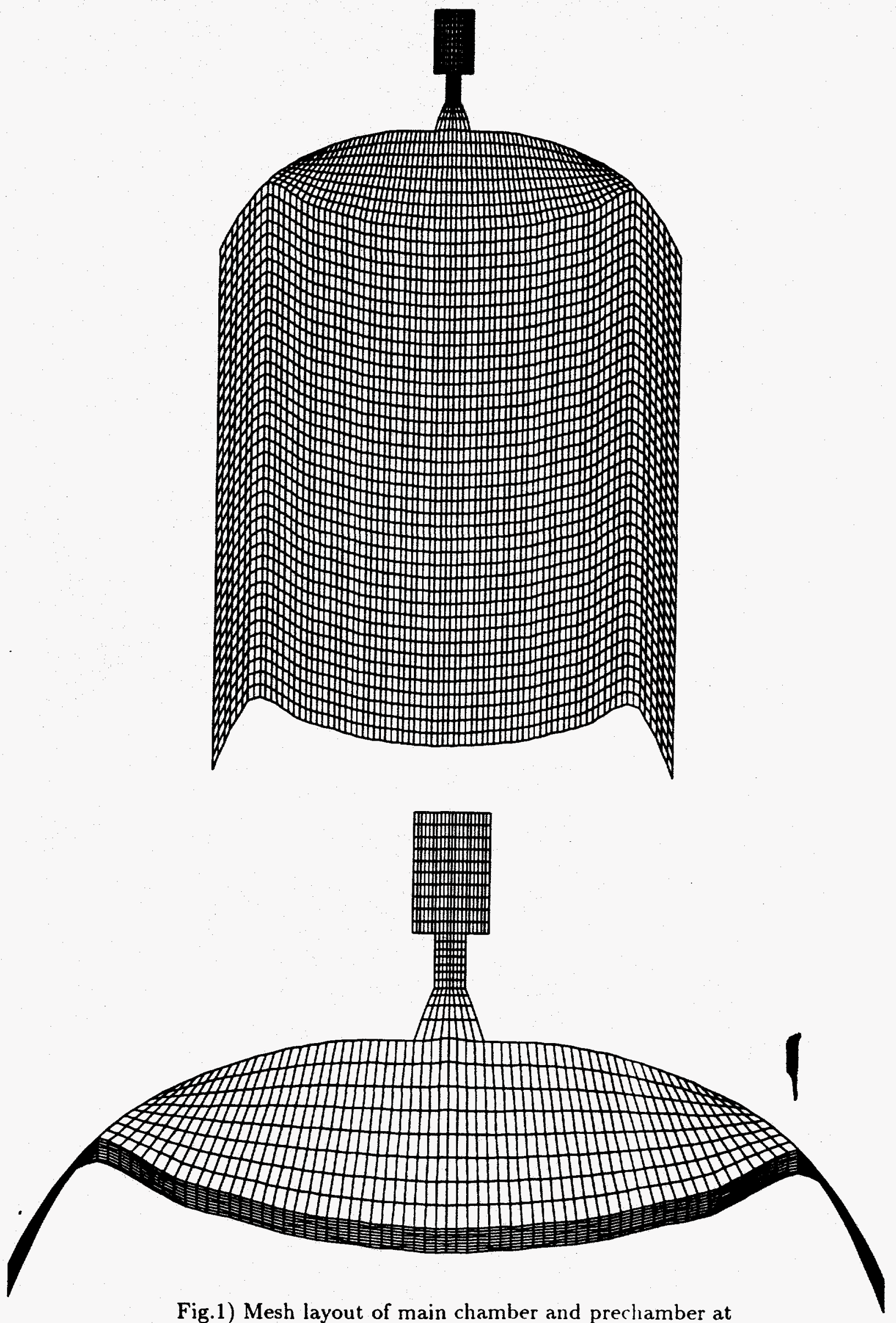

Fig.1) Mesh layout of main chamber and prechamber at

a) Bottom dead center

b) Top dead center 


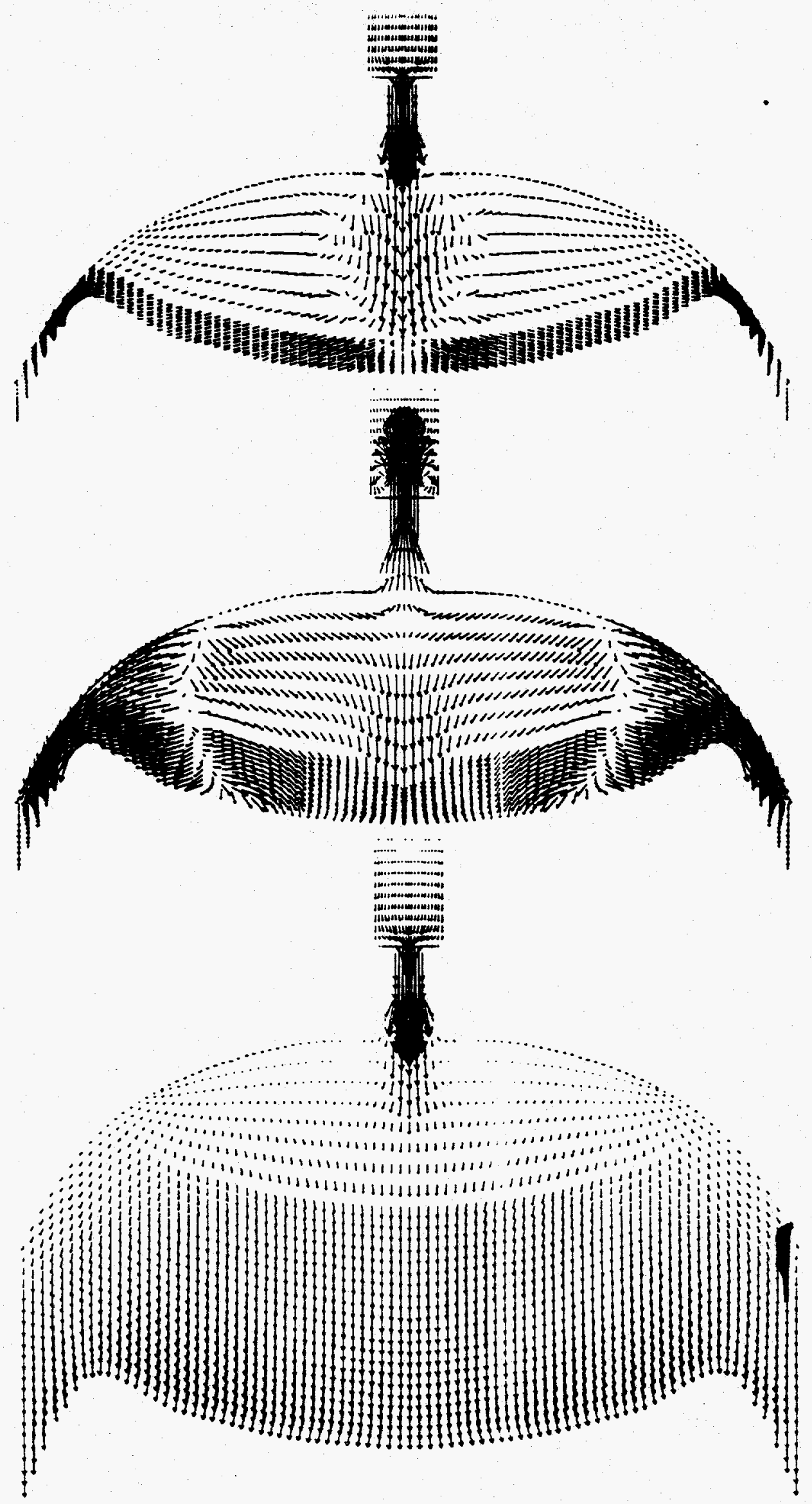

Fig.2) Velocity-field snapshots following ignition, showing three phases dominated by:
a) prechamber burn
b) main chamber burn
c) piston suction 


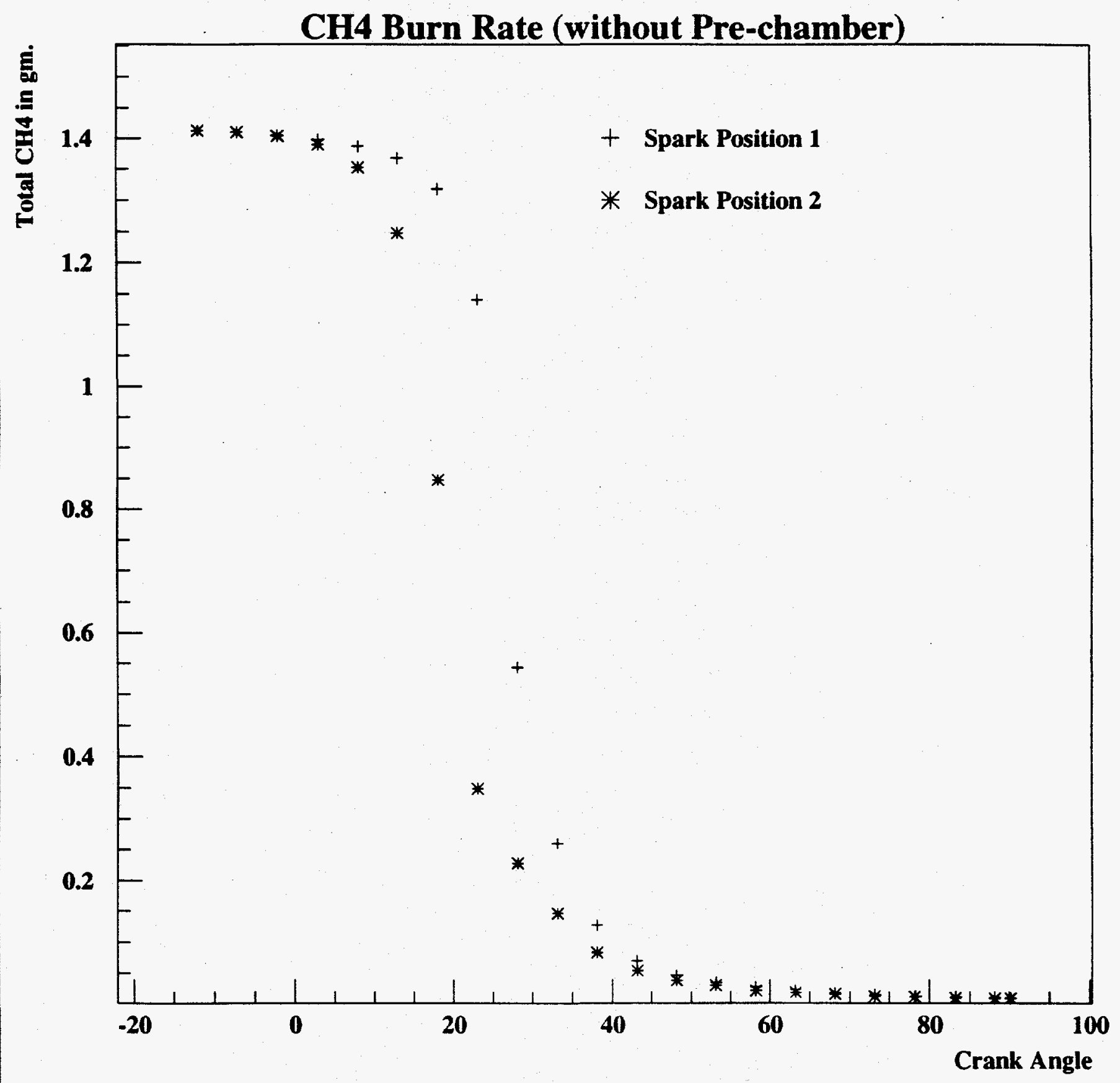

Fig.3) $\mathrm{CH}_{4}$ consumption as a function of crank angle for the two cases with no prechamber. 

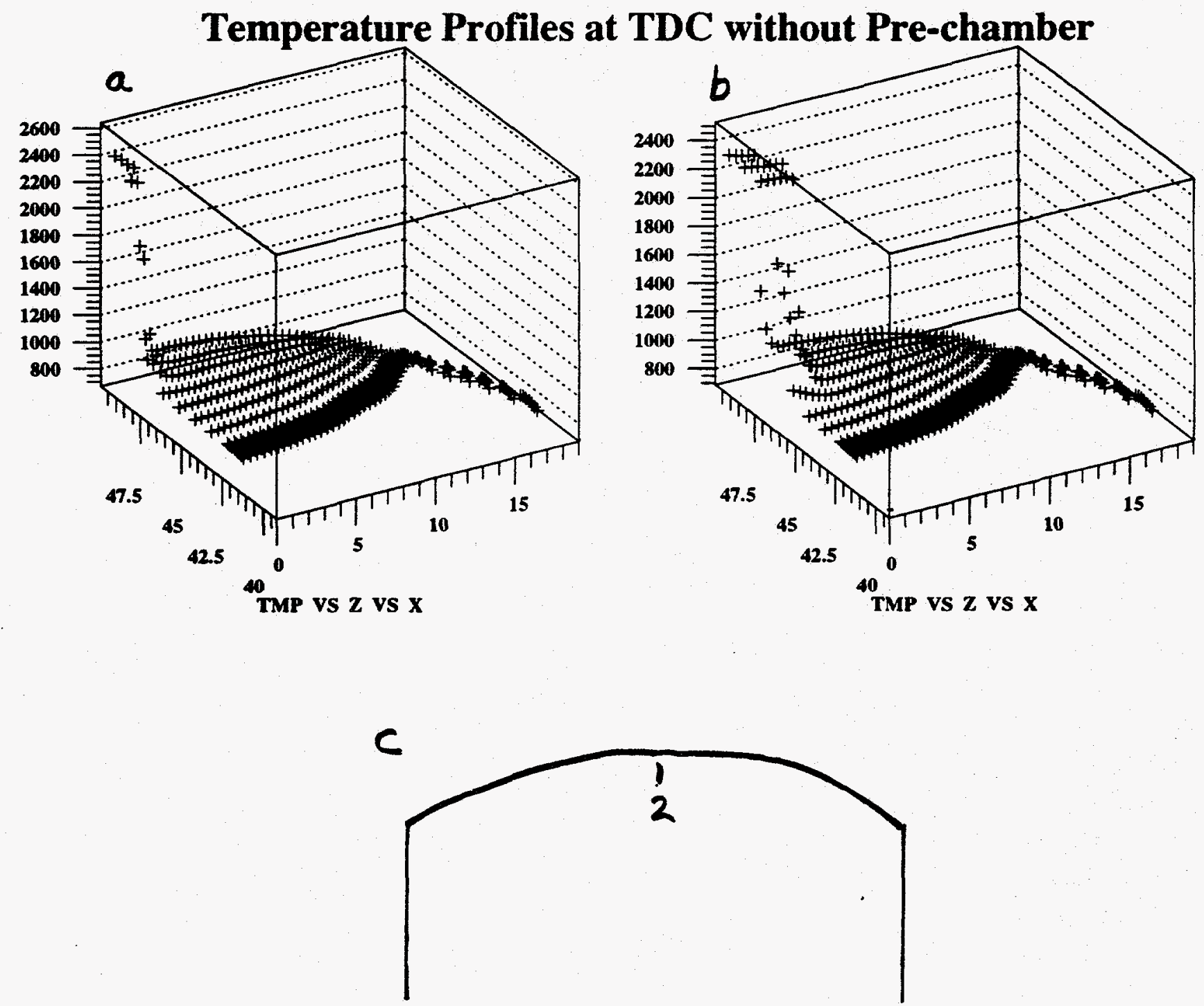

Fig.4) Temperature profile at TDC for the two cases with no prechamber.

a) Spark position 1

b) Spark position 2

c) Key of spark positions 


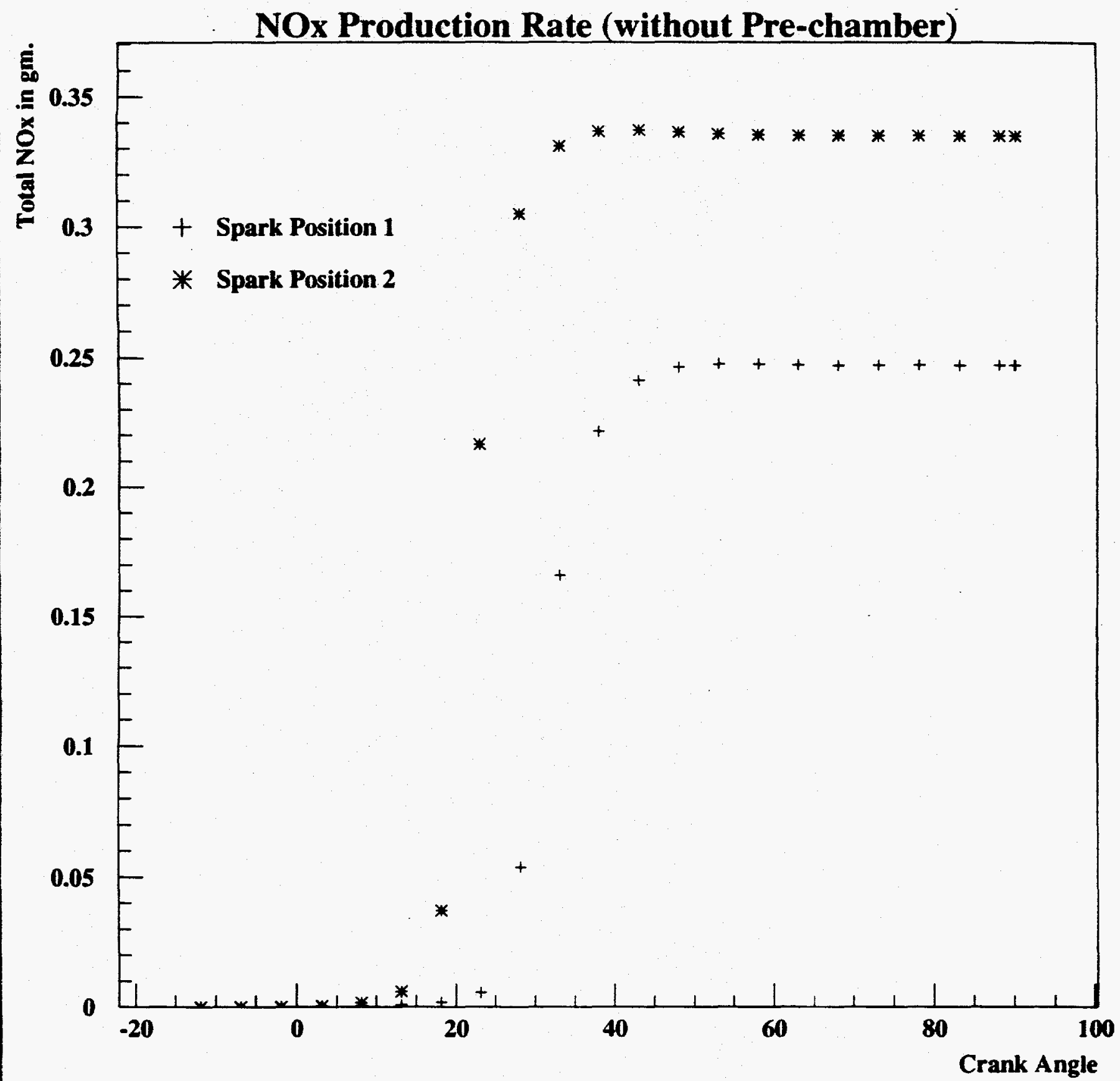

Fig.5) $\mathrm{NO}_{x}$ production as a function of crank angle for the two cases with no prechamber. 


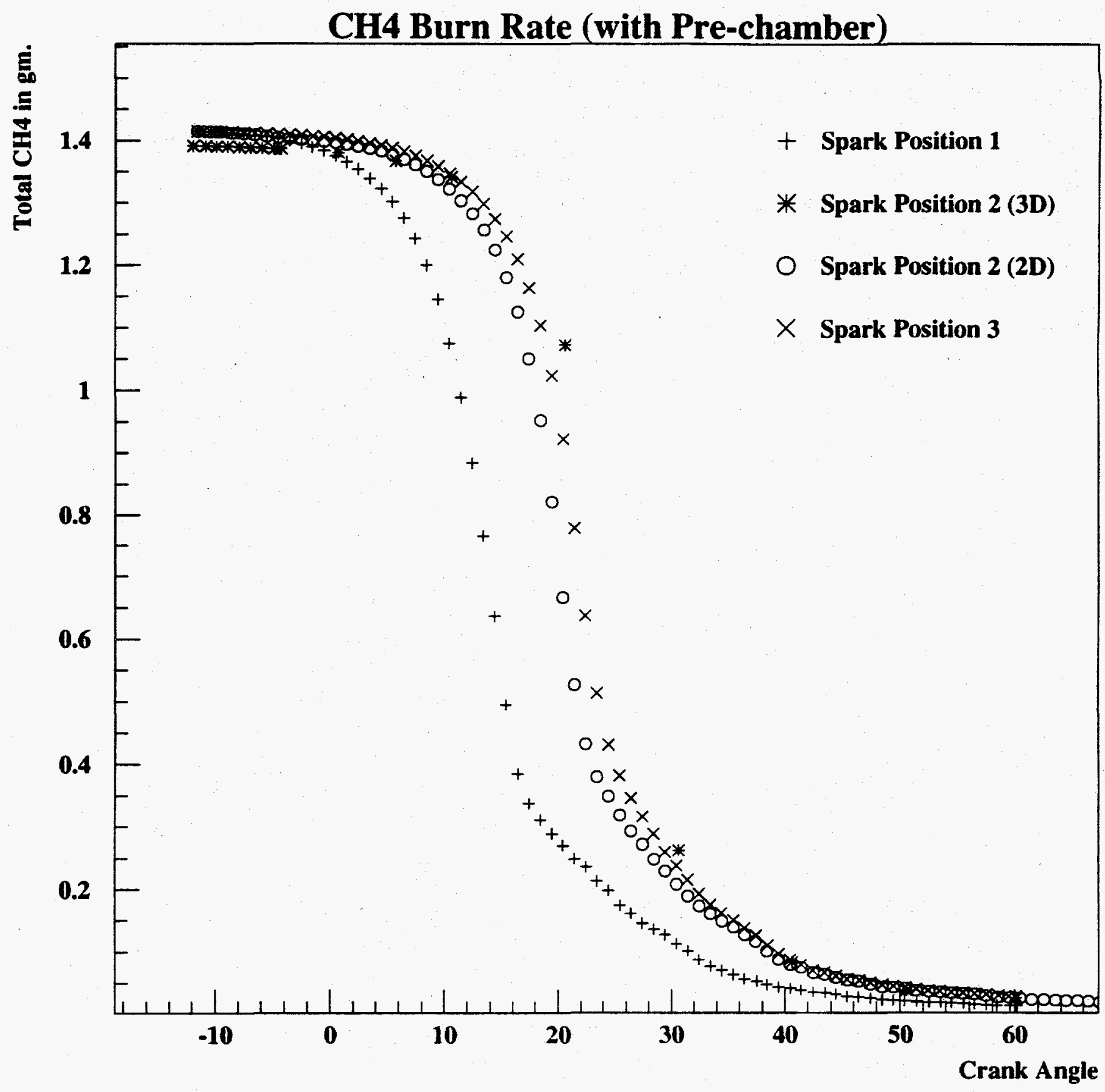

Fig.6) $\mathrm{CH}_{4}$ consumption as a function of crank angle for the four cases with spark position being varied in the prechamber. 

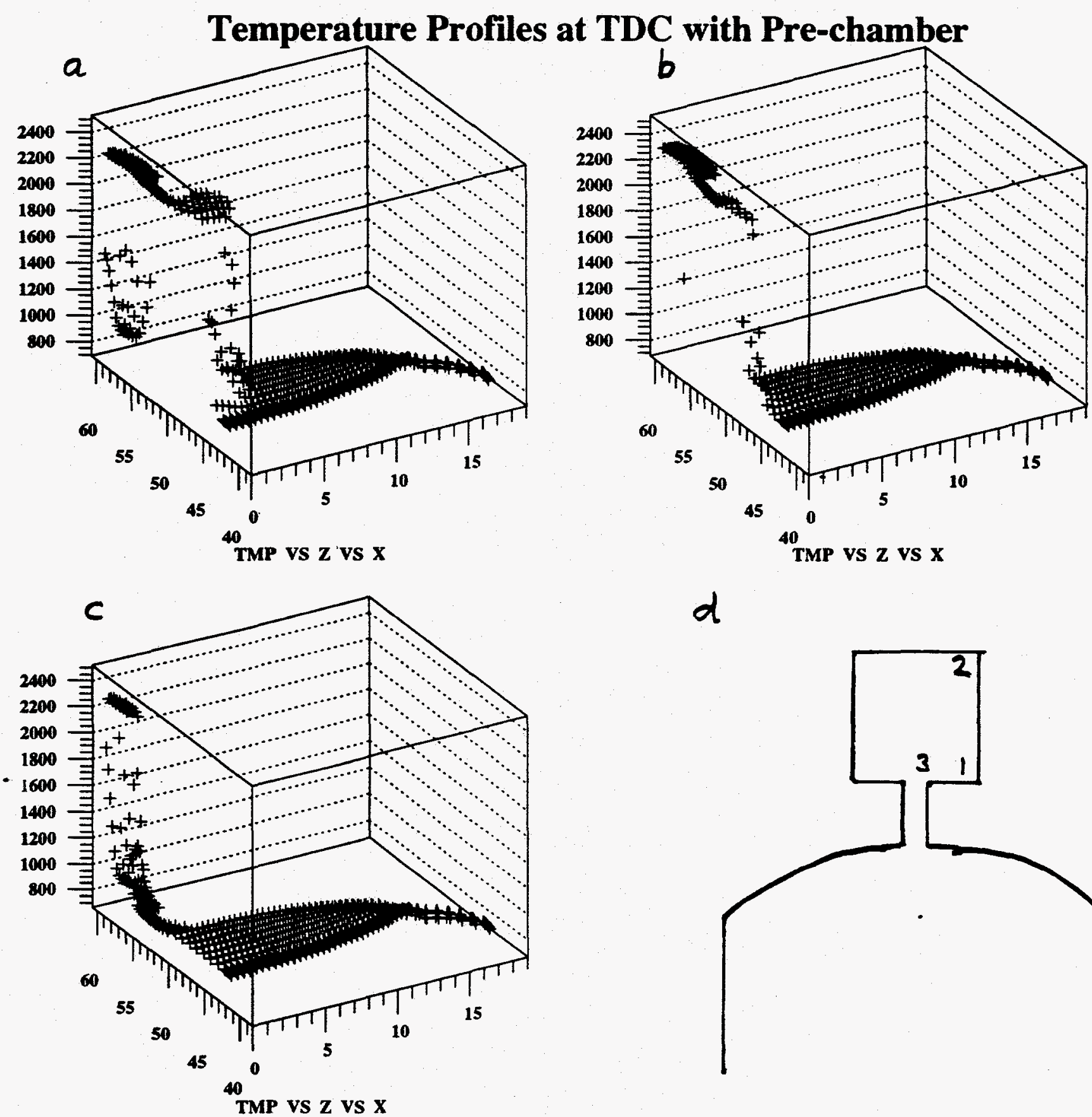

$\alpha$

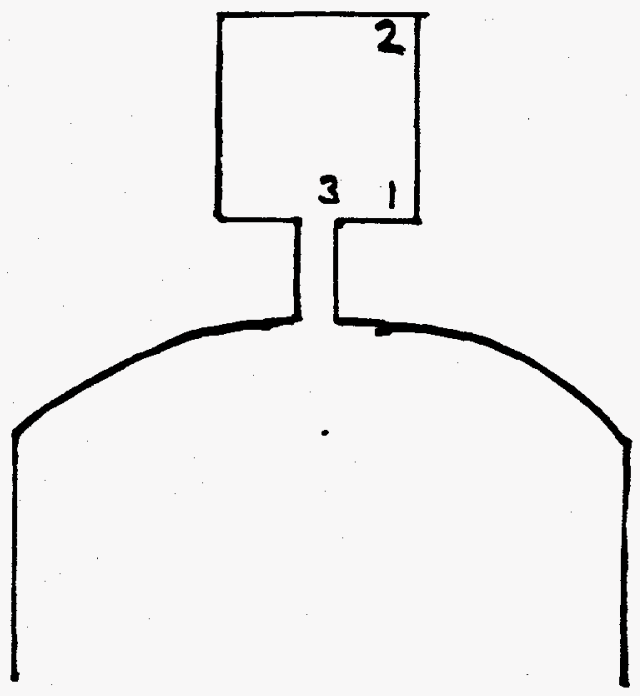

Fig.7) Temperature profile at TDC for the three 2D runs with spark position being varied in the prechamber.
a) Spark position 1
b) Spark position 2
c) Spark position 3
d) Key of spark positions 
NOx Production Rate (with Pre-chamber)

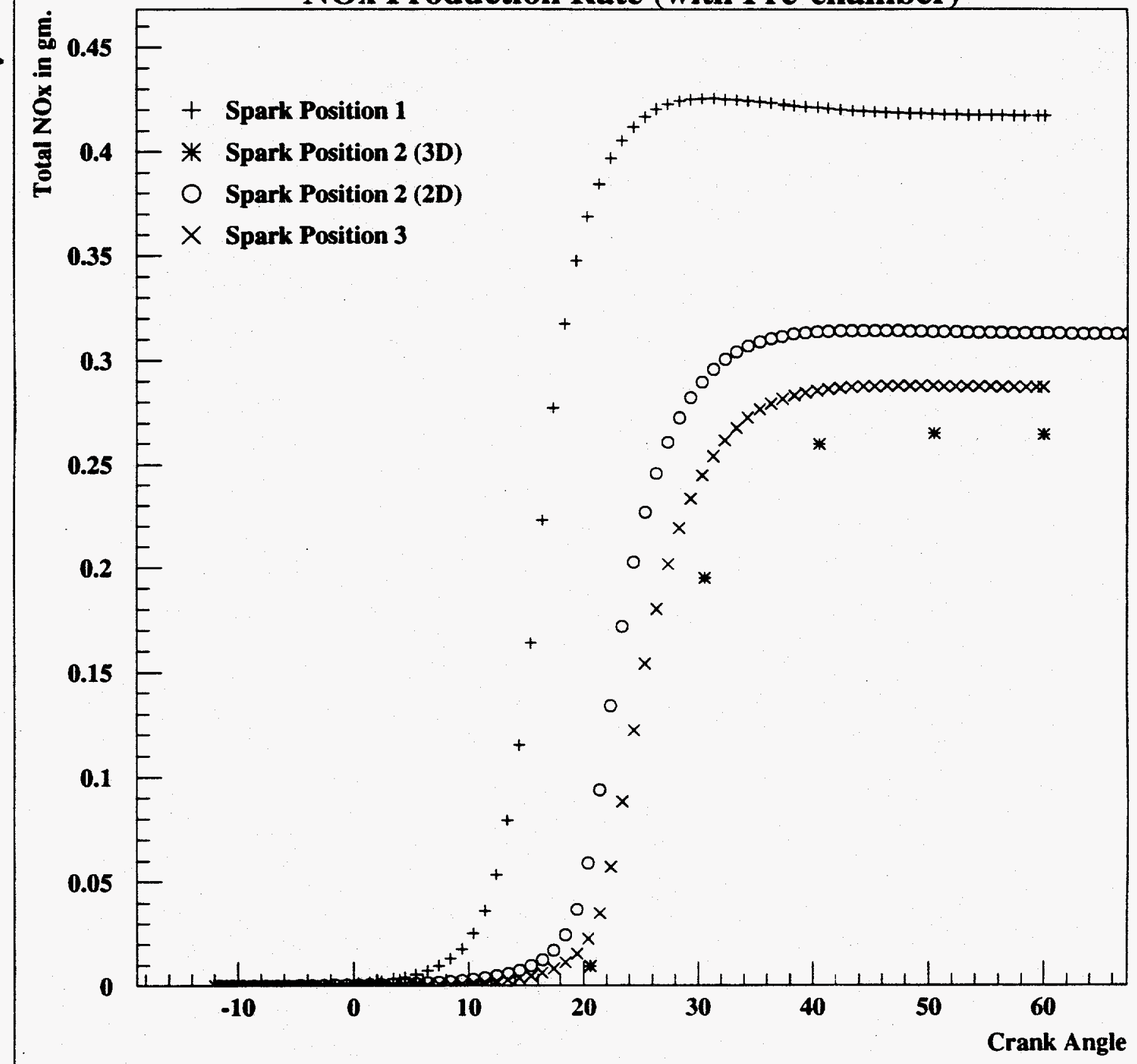

Fig.8) $\mathrm{NO}_{\mathrm{x}}$ production as a function of crank angle for the four cases with spark position being varied in the prechamber. 

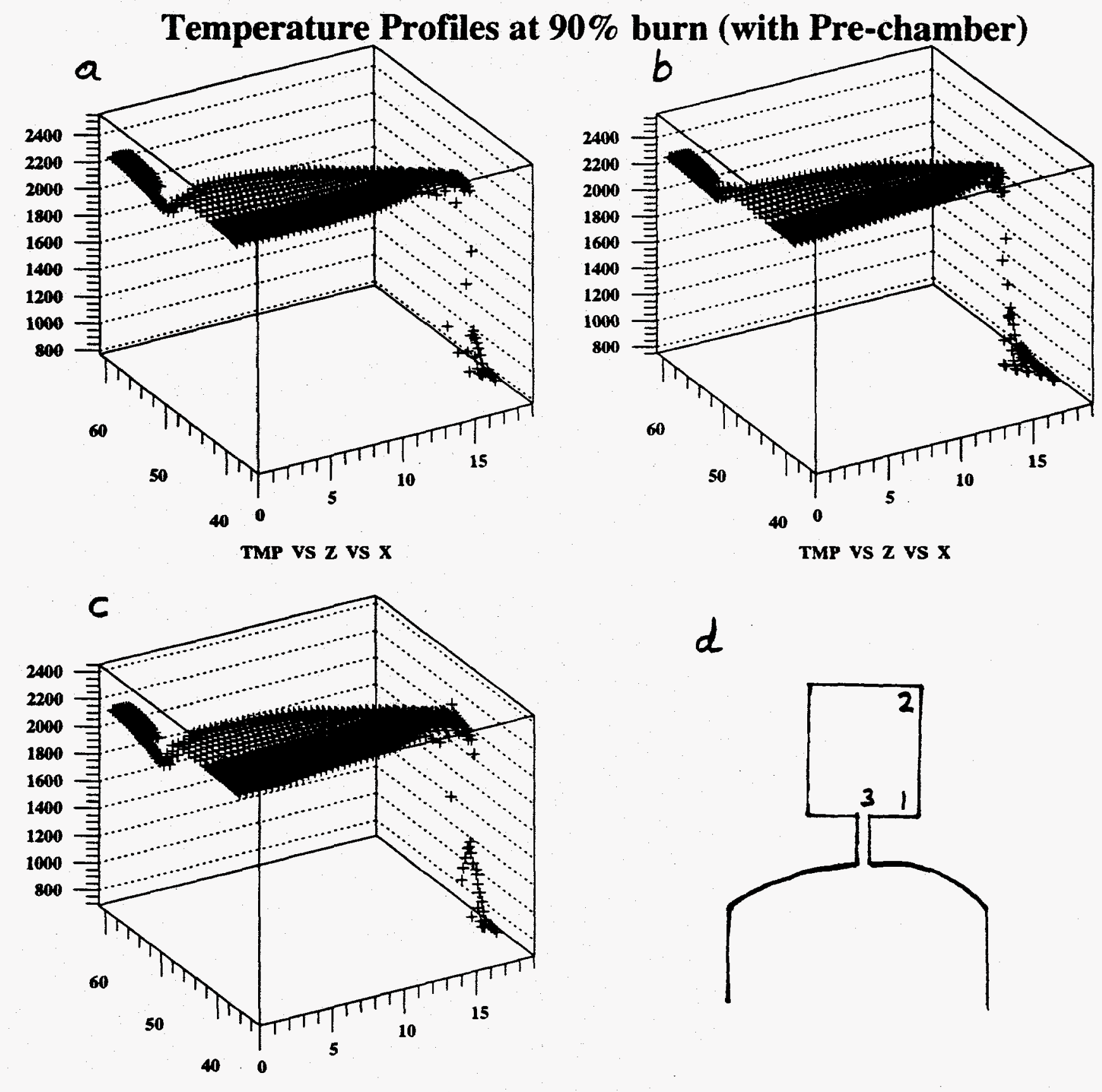

$d$

TMP vs $Z$ vs $\mathrm{X}$

Fig.9) Temperature profile at when $90 \% \mathrm{CH}_{4}$ is consumed for the three 2D runs with spark position being varied in the prechamber.
a) Spark position 1
b) Spark position 2
c) Spark position 3
d) Key of spark positions 
.

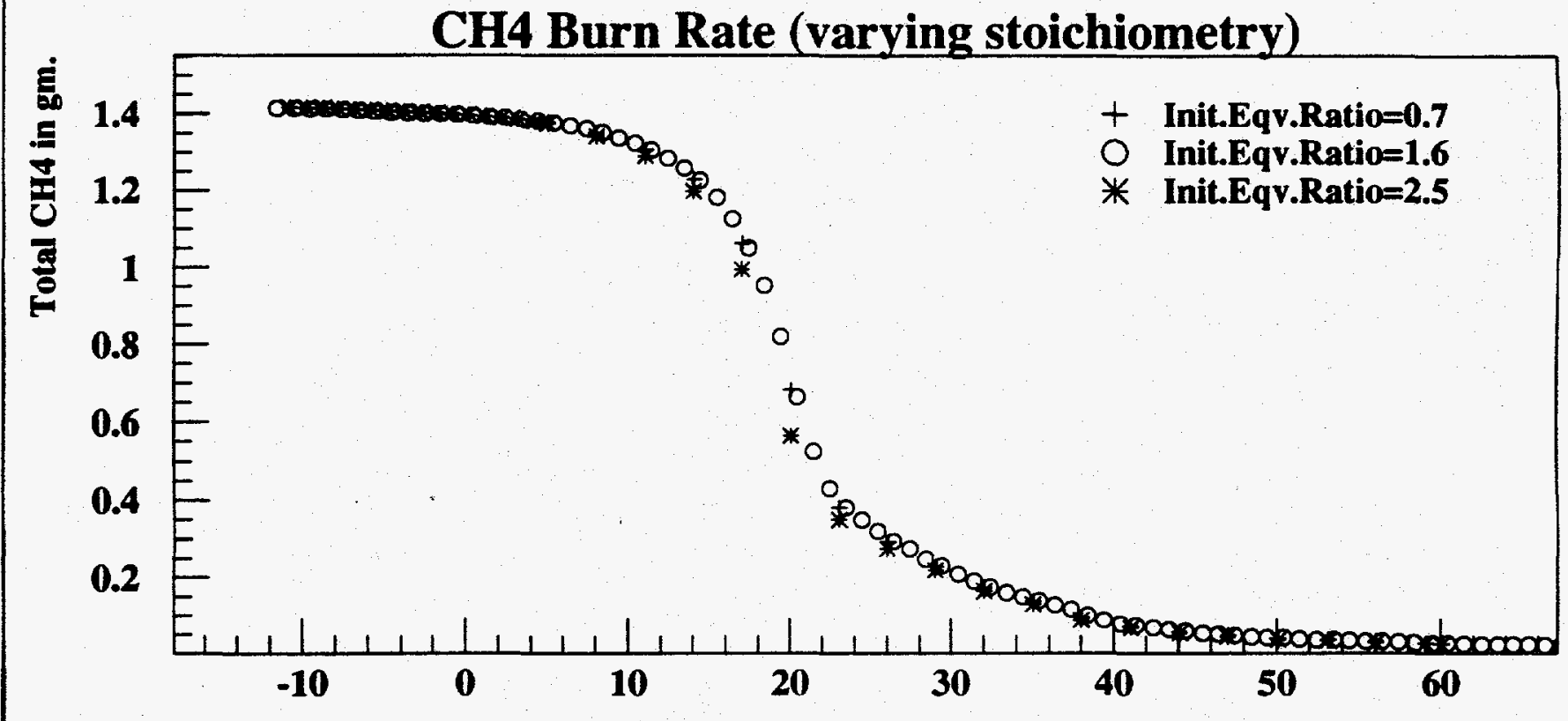

Crank Angle

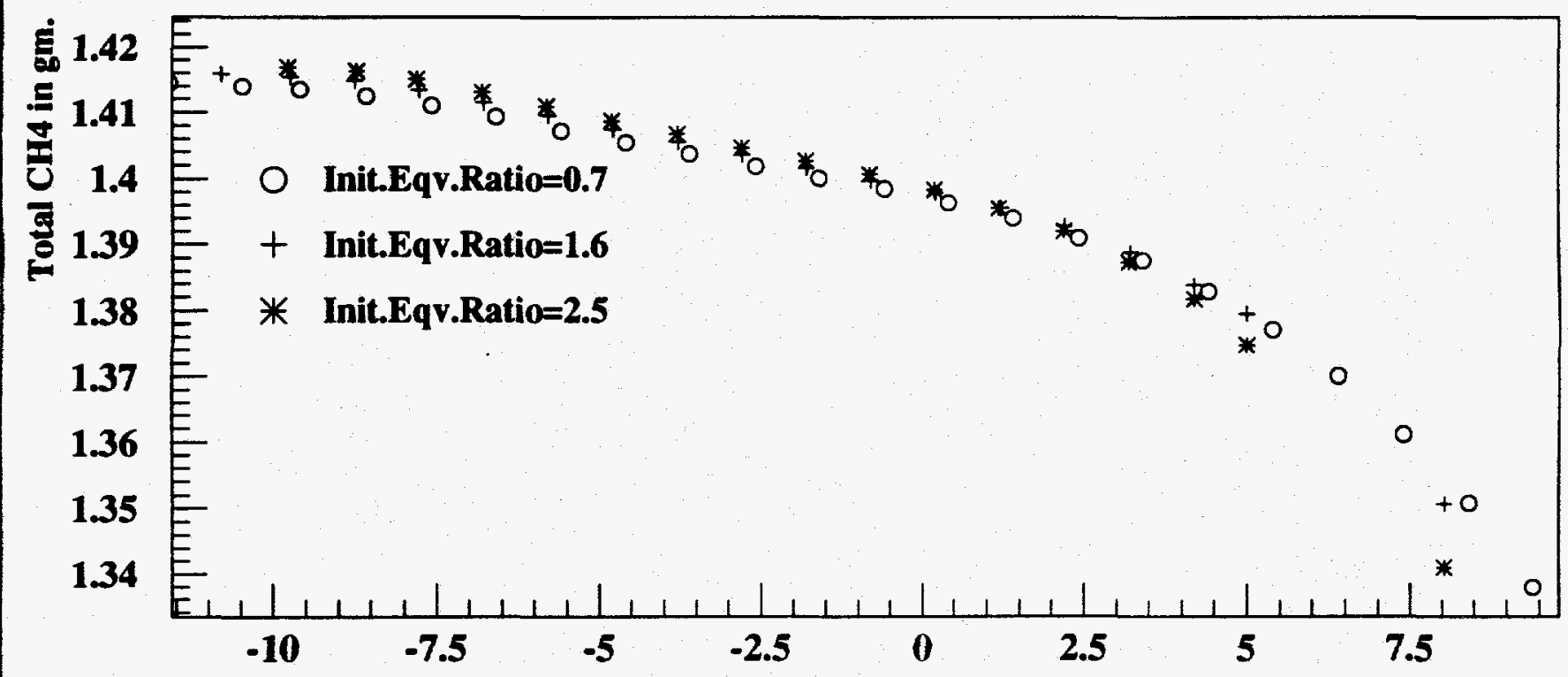

Crank Angle

Fig.10) $\mathrm{CH}_{4}$ consumption as a function of crank angle for the three cases of varying prechamber stoichiometry.
a) Overall burn
b) Initial burn period 


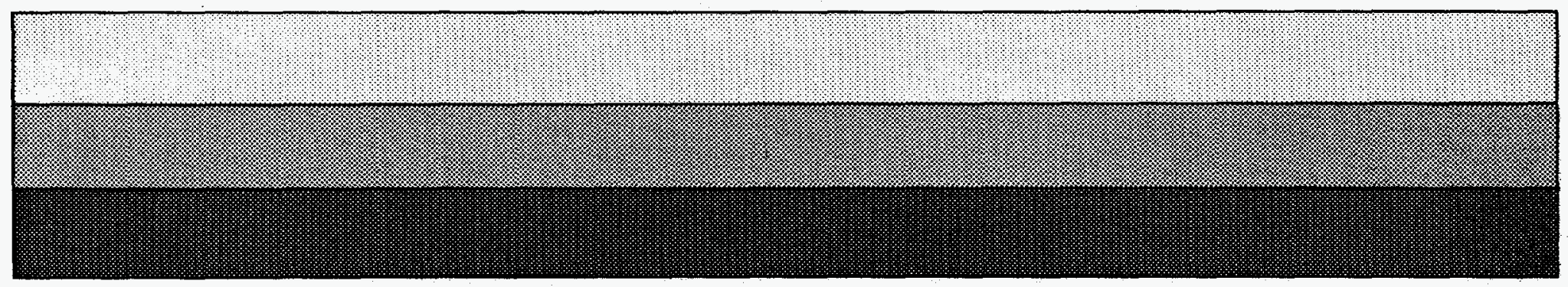

